\title{
Multilingual Gendered Identities: Female Undergraduate Students in London Talk about Heritage Languages
}

Siân Preece, Institute of Education, University of London

\begin{abstract}
In this paper I explore how a group of female university students, mostly British Asian and in their late teens and early twenties, perform femininities in talk about heritage languages. I argue that analysis of this talk reveals ways in which the participants enact 'culturally intelligible' gendered subject positions. This frequently involves negotiating the norms of 'heteronormativity', constituting femininity in terms of marriage, motherhood and maintenance of heritage culture and language, and 'girl power', constituting femininity in terms of youth, sassiness, glamour and individualism. For these young women, I ask whether higher education can become a site in which they have the opportunities to explore these identifications and examine other ways of imagining the self and what their stories suggest about 'doing being' a young British Asian woman in London.
\end{abstract}

Key words: gendered identity, subject positions, multilingualism, femininities, heritage language, higher education

English I would say is my everyday language, I think in English as well ... it's part of my everyday. Urdu is ... part of my everyday as well ... I communicate with my parents in Urdu [and] the rest of my family. So English and Urdu are both equal in my mind (Aisha, Interview 1).

Sometimes my parents ... talk in Tamil and then suddenly they change into English ... when I come to university I tend to use a lot of English but then when I'm with my home people ... they start talking Tamil and ... I just start talking in Tamil and ... when they start talking [in] English, I reply ... in English ... So it goes ... on and off (Sita, Interview 1).

These quotes are from interviews with Aisha and Sita, two British Asian women in the first year of their studies at Millennium Universityi. Both position themselves as 'multilingual', in that they use English and 'community' languages common in urban Britain (Martin-Jones and Jones, 2000). Both suggest they are 'balanced bilinguals' (Macnamara, 1967, 1969) with an equal proficiency in English and their heritage languages. Nevertheless, both have a much greater command of English than their 'mother tongue'. This is in keeping with the work on language 'expertise', 'affiliation' and 'inheritance' established by Ben Rampton, Roxy Harris and Constant Leung (Harris, 1997, Leung, Harris and Rampton, 1997, Rampton, 1990) that has consistently shown that British-born ethnic minority urban youth not only have greater levels of 'expertise', i.e. proficiency, in English, in relation to their heritage languages, but also do not necessarily feel much 'affiliation', in the form of strong emotional attachment, to their

s.preece@ioe.ac.uk - - 1 - 
heritage language as a language of 'inheritance'. In fact, in common with their White British counterparts, many identify more readily with vernacular English.

Taking Rampton et al's work as a starting point, in this article, I explore affiliation to heritage languages in relation to gender as a 'dimension' of identity (Cameron, 2005). In particular, I consider ways in which gender is performed in talk about heritage languages. While previous work focuses on school-aged adolescents, the participants discussed here are first-year undergraduate students. As such, there may be differences in their outlook, for as David Block (2006) argues, language affiliations can 'shift dramatically' during a person's lifespan (p. 36). Although I have data from both male and female participants, here I intend to focus on the female participants. This is due to constraints of space, the fact that the women often had more to say about heritage languages when with peers and my wish to contribute to literature on femininities with British ethnic minority participants.

Another consideration is the discussion on student diversity in British higher education. While there are growing numbers of students from ethnic minority communities entering London's universities, student diversity still tends to be discussed in terms of essentialised groupings. There is, as yet, little debate on students in terms of 'identifications, subjectivities and positions' (Baxter, 2003, Butler, 1990, Weedon, 1997). It is my aim, therefore, to make some contribution from this latter standpoint.

\section{Setting}

This paper is based on data I collected at Millennium University over a two-year period. The data come from a research project (Preece, 2006b) exploring gendered identities and identifications with multilingual undergraduates, most of whom were London residents who were British-born and educated, from working-class backgrounds and in their late teens and early twenties. All had 'newcomer' (Lave and Wenger, 1991) status, in that they were undergoing the process of transition to higher education and were largely unfamiliar with the systems and practices prevalent at Millennium. All were regarded as from widening participation ${ }^{\mathrm{ii}}$ backgrounds, either because they were the first person in their family to enter university and/ or because of their family's social class.

Similarly to the adolescents in Rampton et al's work, many discussed English as a 'slang/ posh' dichotomy, with many displaying strong identification with 'slang' and discomfort with 'posh' . While the 'slang' of urban youth has been discussed in sociolinguistics' literature as 'local multi-ethnic vernacular' or 'community English' (Hewitt, 1992), I prefer the term 'peer-group English', as the participants' preferred language practices had developed in peer group 'communities of practice' that were strongly oriented to popular culture discourses. Defined as a 'set of relations among persons, activity, and world, over time and in relation with other tangential and overlapping communities of practice' (Lave and Wenger, 1991, p. 98), 'community of practice' has been a helpful tool for considering the dynamics and relationships between the participants and for considering how they go about 'balancing the self' (Eckert and McConnell-Ginet, 2003, p. 58 ), in other words constructing a coherent sense of self, as they negotiate the demands and 
practices of their undergraduate peer group, the University, and their family.

All the participants were taking an academic writing programme $\mathrm{e}^{\mathrm{iii}}$ designed to improve their prospects at Millennium. This programme, on which I was a teacher, forms the setting for the first stage of the research. I kept field notes, audio-recorded small group discussions of all-female, all-male and mixed-sex groups in the classroom and collected questionnaire data. In the second phase of the research in the students' second year, I enlisted former class members for a series of interviews.

Much of the data from the female participants suggests that they had similar concerns to young ethnic minority women in other research (e.g. Bhatti, 1999, Pichler, 2001, Shain, 2003). These studies have challenged stereotypes, particularly of Asian femininities. Ghalaza Bhatti (1999), for example, explores ways in which academic achievement enables some British Asian girls to perform the 'delicate art of balance' (p. 164) in which maintaining family 'izzat' (honour), through being both 'shareef' (respectable) and academically successful (p. 167), helped her participants gain more freedom during adolescence. Elsewhere, Pia Pichler (2001) explores the construction of 'bi-cultural' femininities, in which British Bangladeshi teenage girls find ways of balancing and blending culturally conservative "good girl" discourses with the practices of "tough girl" discourses in British popular culture (p. 34).

Norms regulating femininities in different contexts have been constant themes in feminist literature, as have ways in which women from both majority and minority communities have found of subverting and resisting these norms. To explore these issues, I will focus on ways in which the participants performed femininities as they negotiated discursive 'subject positions', defined by Chris Weedon (1997) as 'ways of being an individual', available to them in more traditional discourses and those associated with popular culture. Following Jennifer Coates (1997), I contend that these subject positions are gendered, enabling the participants to present themselves as gendered beings in relation to others. Drawing on Judith Butler (1990), I view gender as 'performative' in that it comes into existence through 'doing'. As Butler argues, gender has also become messily entangled with 'biological sex', giving rise to 'culturally intelligible' ways of doing gender in which heterosexuality is seen as the norm within a discourse of 'heteronormativity', as the

system which prescribes, enjoins, rewards, and naturalizes a particularly kind of heterosexuality-monogamous, reproductive, and based on conventionally complementary gender roles-as the norm on which social arrangements should be based (Cameron, 2005, p. 489).

In the following sections, I firstly draw on data from the all-female peer-groups and then from the interviews with Sita and Aishaiv to explore femininities in talk about heritage languages. In the data extracts, I have transcribed the group discussions based on conventions by Coates (1996), outlined at the end of the paper. To aid the readability of the interviews, I have used standardised spelling and punctuation, adding words in square brackets and suspension points where words are omitted. 


\title{
Talk about heritage languages with female peers in the classroom
}

\author{
"In-Laws"
}

Female group 1 consists of Leela (aged 19), from a Gujarati-speaking family, Biba (aged 22), from an Arabic-speaking Moroccan family, and Awino (aged 32), a mature student from a Swahili and Kamba-speaking family. While Leela and Biba are British-born and educated, Awino grew up in Kenya where she attended English-medium schools. After coming to Britain in her early twenties, Awino worked for ten years before entering university. While Leela and Biba have established a friendship, Awino appeared a more peripheral group member. In the first extract, Leela is talking about her experience of Gujarati classes and expressing regret about her limited expertise in Gujarati. As the extract illustrates, this talk enables Leela, Biba and Awino to explore their heritage language in relation to parental expectations, marriage and motherhood.

$\mathrm{L}=$ Leela, $\mathrm{B}=\mathrm{Biba}, \mathrm{A}=\mathrm{Awino}$

1. L: $\quad$ when I was younger my mum PUT me in Gujara- Gujarati school and then she

2. B: yeah

3. L: She goes "you've GOT to learn your language"

4. B: yes

5. L: "because it will be embarrassing when you're older (.) when [you meet [your in-laws and that"

6: A:

7: B:

8: A:

[I feel embarrassed (.) I [feel embarrassed right now

[yeah yeah

9. L: $\quad$ yeah

10. A: they should

11.L: $\quad$ yeah [and-

12. A: $\quad$ it's very important=

13: L: $\quad=$ you know WHAT? about (.) two months there I couldn't stand it I said "mum I don't want to learn (.) bye bye"

14. A: $\quad \% \mathrm{~mm} \%$

15: L: $\quad$ and she (.) I REGRET it to this day

16: B: yeah

Adopting her mother's voice (turns 1-5), Leela suggests that she had to learn Gujarati not only because of ethnicity and culture, but also because of gender. Her femininity is constituted through a heteronormative discourse in which her mother positions her both as heterosexual and as a future bride, who will 'naturally' marry a man symbolising her cultural heritage. In order to be a dutiful daughter and wife, she needs to be able to converse in Gujarati, not only with her parents, but also her future in-laws, who are 
positioned as non-English speakers. Lack of fluency in Gujarati appears potentially embarrassing, although it is unclear whether for Leela or her mother. In later turns, Leela reverts to her own voice to resist this positioning with a forceful utterance that she 'could not stand' community school and had no desire to learn Gujarati (turn 13). She immediately counters this by expressing regret for not following her mother's advice (turn 15), in which she orients to a dominant discourse of the family in which, as Coates (1996) points out, daughters are dutiful and honour their parents (p. 241). Despite initially subverting this discourse, Leela takes care to present herself as at fault for not following her mother's wishes.

Both Biba and Awino identify with this traditional discourse of family relations. Awino speaks as a mother, reproducing a traditional mother-child discourse in which children honour their mothers by using the 'mother tongue' (turns 8-12). Awino's desire for her children to speak '(her) language' is a reference to her heritage languages. Perhaps this arises from Awino's identification with her Kenyan 'imagined community' (Anderson, 1991), for while Awino is a British citizen, in other sections of the data she presents herself as 'fully Kenyan' and resists Britishness" . Later, however, she seems to contradict this by presenting her Kenyan accent as embarrassing. Biba's emphatic statement that she feels 'embarrassed right now' (turn 7) appears to refer to her positioning in her family as later she presents her inexpert use of Arabic as excluding her from the extended family. While Biba appears to accept her positioning as a 'dutiful daughter', ashamed by her lack of expertise in her 'mother tongue', she also resists this positioning through presenting herself as 'more westernised than ... Moroccan', with her own 'more westernised' interpretations of her 'morals, religion and culture'.

\section{"You know how parents are"}

The members of female group 2 are Maya (aged 19), Seema (aged 19), who are both British-born and from Gujarati-speaking families, and Deena (aged 20), a Mauritian student from a French Creole speaking family. At the time of the study, Deena had been in Britain for less than a year. While Maya and Seema get on well, Deena often seems on the fringes of the group, which seemed related to difficulties in following group interactions. In the following extract, Seema and Maya are discussing their use of English and Gujarati at home; Deena remains silent. Both Maya and Seema present their use of their heritage languages with their parents as 'fragmented' (Harris, 1999). Their talk not only suggests shared knowledge regarding home life and parent-daughter relations, but also ambivalence about a 'dutiful daughter' positioning.

$\mathrm{S}=$ Seema, $\mathrm{M}=$ Maya

1. S: I speak English (.) [mixed like (.) I don't know

2. M: [talked with $((\mathrm{xx}))$ and I was like $($.$) half and half=$

3. S: =half yeah: (1) but most of the time it's in English okay (.) now they've like (.) changed (1)

4. M: they know it

5. S: they think it's bad though (.) you know how parents are=

6. M: =it's very bad we don't know the language <laughs> 
Here talk about heritage language prompts covertness through the ambiguous 'they' to refer to parents and parental reluctance to accept their children's way of using heritage languages. The impersonal pronoun and pauses suggest a subversive and rather uncomfortable positioning. This is emphasised in the final turns in which Seema positions her parents as unhappy with her use of Gujarati. Her statement 'you know how parents are' shows that she expects Maya to understand her experiences of parentdaughter relations. Maya's final utterance can be read in various ways. She may be enacting a parental disapproving voice with her 'it's very bad we don't know the language'. However, the accompanying laughter is suggestive of an in joke based on a common understanding of parental behaviour. Maya may also feel genuine concern about her expertise in Gujarati and the laughter may mask anxieties about not fulfilling parental expectations.

\section{"Now then girls"}

The third all-female group is composed of Davinder (aged 19), Saba (aged 19), Aisha (aged 18) and Zarina (aged 19), all British Asian females from Urdu/ Punjabi-speaking families. Davinder and Saba are close friends and core members of the group while Aisha and Zarina are more peripheral members. All initially adopt 'girl power' subject positions. Defined as a 'self-reliant attitude among girls and young women manifested in ambition, assertiveness and individualism' (OED, 2001), 'girl power' constitutes femininity in terms of sassiness, youth, glamour, consumerism and individualism, performed through doing being a 'ladette', in which, as Imelda Whelehan (2000) comments, 'normal "girls" like nothing better than to have a laugh with their mates' ( $p$. 40). In this group, ladette femininity manifests itself through appearance, behaviour and talk. All pay careful attention to the latest trends in clothing, presenting themselves as stylish young women; all report reading young women's lifestyle magazines, presenting themselves as unashamedly 'into fashion' and celebrity culture. Saba and Davinder often engage in 'sassy' behaviour in the classroom, particularly with male peers. However, while all approach peer group activities in a playful manner, Aisha and Zarina sometimes attempt to do more serious talk, particularly when discussing family relations. This is illustrated in part 1 of the following extract, in which all start playfully when talking about themselves in relation to other students. However, in part 2, when the talk turns to heritage languages, Aisha and Zarina attempt to conform to a more 'dutiful daughter' position.

$\mathrm{S}=$ Saba, $\mathrm{D}=$ Davinder, $\mathrm{A}=$ Aisha, $\mathrm{Z}=$ Zarina, $\mathrm{F}=$ unknown, $\mathrm{ALL}=$ unison

Part 1:

1. S: okay (.) now then <tape paused> girls (.) HOW do you SEE YOURSELF in RELATION (.) to a) other students in your year? <reading aloud>

2. D: erm/ (.) okay erm there's like loads of different people and it's completely different because (.) they're not all the same age as us because it's like at the end (.) you're talking about <laughs> same age as us [<laughs>

3. S:

[thank you 
Davinder (.) Aisha?

4. All: <laughter> (4) <tape paused>

5. A: I think there are a lot of students that are mature (.) so that we can't (.) relate to 'em <laughs>

6. S: thank you Aisha <laughs><recording turned off/on> (2) okay right in relation to the other $($.) member/ I mean=

7. Z: $\quad=$ YEAH I agree with the points that are made (.) that's what I would say as well

8. S: all right (.) I think that erm (.) there's different type of people around and=

9. D: =it's LOADS of people we hardly (.) $[\mathrm{mm}$

10. S:

11. D:

of the whole university

[yeah it's [difficult

[we're only about two out

12. All: <laughter>

13. S: THANK YOU <laughs $>$ DAVINDER

14. All: <laughter><tape turned off>

<approximately 2 minutes of transcript omitted>

Part 2:

15. S: how do you see yourself in relation to these languages? <reading aloud> Davinder?

16. D: okay I'm quite good at English as in speaking and stuff but er Punjabi I'm not that good (2)

17. A: okay I can speak Urdu quite well and read it and write it (.) and er I keep in [touch with my cousins as well so that I can practise Urdu that way=

18. F: $\quad$ wow

19. Z: =that's really $[$ good

20. A: [and (.) I'm okay at English as well

21. Z: I'm okay with English but Urdu (.) I can't write it that well=

22. A: =can you read it?

23. Z: yeah I can read it

24. D: $\mathrm{RAH}=$

25. S: =basically ME (.) I'm okay in English and Punjabi I cannot read it AT ALL (.) so that's about it (.) all right moving onto number six (.) HO:W do you THINK you are ah:::: (3) <laughs> we' re finished now thank you very much and er Davinder wants to say "bye"

26. All: <laughter>

27. S: everyone say "bye" now (.)

28. All: BYE:: <laughter>

In the opening turn, Saba positions them all as 'girls'. Her utterance sounds playful, suggesting she is inviting her peers to have fun, and also inclusive; the others can be included through cooperating in the performance of this playful 'ladette' persona.

Davinder responds by positioning them as different from other students with a reference 
to age. Again the tone is playful and the others respond with laughter. The 4-second pause following this suggests Aisha is considering her response. She collaborates by voicing what has only been hinted at so far, that other students are 'mature' and therefore difficult to 'relate to'. In this context, 'mature' appears to refer to age and/ or outlook. Following Zarina's cooperation, Saba and Davinder work to maintain this positioning with this section being rounded off with more communal laughter. However, when they move onto the subject of heritage languages (part 2), Aisha and Zarina adopt a more serious persona, displaying identification with their heritage languages and taking control of the floor to discuss their use of Urdu. When it appears that their talk is getting serious, Davinder interrupts with 'RAH', the volume and tone creating ambiguity over whether she is being complimentary or sarcastic. In a latched turn, the volume of Saba's 'ME', her emphatic statement about not being able to read in Punjabi, and her move to change the topic effectively prevents further discussion on heritage languages. Perhaps Saba and Davinder perceive this talk as boring, overly serious, or a threat to light-hearted sociability. Their resistance to discussing heritage languages suggests that for them the peer group provides a space for forgetting about, rather than dwelling on, family relations. This resonates with the young women in Bhatti's (1999) study, who characterised college as an escape mechanism from home, a place to 'do what the hell you like' (p. 167).

\title{
Talk about heritage languages in the interviews
}

\begin{abstract}
Aisha
"You want to be a part of it"

Born in 1982 in London, Aisha is the oldest child of an Urdu/ Punjabi-speaking Pakistani family. Aisha lives at home with her parents, her two younger sisters and an uncle. In the interviews, Aisha presents her relationship with her mother as primarily in Urdu, her father as in English and Urdu, and her extended family in Pakistan in Urdu. In common with many of the British-born participants, Aisha presents her relationship with her siblings as primarily in English. However, Aisha comments that the setting influences her language choice, positioning herself as adapting to the 'environment' to ensure inclusion in the group. In the following extract, Aisha suggests that her identification with Urdu is a way of building relationships with family and friends.
\end{abstract}

A: [The language] depends on the environment ... When we're all in Pakistan we all communicate in Urdu but then [in London] we all communicate in English ...

SP: And when you have family gatherings and ... there's lots of people together, do you find that you are talking more in Urdu or more in English?

A: $\quad$ More in Urdu definitely because everyone else is speaking Urdu ... so you don't want to feel left out ... you want to be a part of it ...

SP: What about with your friends? ... Do you speak most of the time in English with your friends? 
A: $\quad$ Yes, all the time ... It's the same thing as my sisters ... it's ... the environment like in uni, it's English [because] everyone speaks English, so you want to be part of it ...

SP: And is it the same with friends who would speak Urdu?

A: Yes... but if they come round my house ... there's a different environment so then maybe we would speak Urdu sometimes and mix it in more with the English (Interview 1).

Having the ability to switch easily between Urdu and English appears to facilitate participation in family and peer group interactions. As Aisha presents herself as not wanting to be 'left out', this may have encouraged her to develop her affiliation with and expertise in Urdu. According to a large body of literature (e.g. Coates, 1996, Hey, 1996), talk plays a major role in establishing and maintaining friendships for women. While there is a danger of over-generalising about women using talk to establish 'rapport' (Tannen, 1990), in the interviews, Aisha frequently styles herself as concerned with social relationships, fitting into the 'environment' and working to maintain cordiality. This persona is highly oriented to traditional discourses that position women as 'naturally' disposed to co-operative relationships.

\section{"My mum used to read to me"}

The interview setting also gave Aisha an opportunity to elaborate on the language practices of her home. Throughout the interviews, she recalls memories of learning Urdu with her mother, constructing her heritage language as facilitating an intimate motherdaughter relationship:

SP: I notice as well <looking at Aisha's questionnaire> that you said that it was quite easy to read in Urdu ... and I wondered how you had learnt that?

A: I did GCSE and A-level Urdu at my previous school so that is why ... but when I was really young my mum used to read to me in Urdu, she used to speak to me in Urdu, she used to ... show me Urdu books and ... that is why I picked it up (Interview 1).

Her depiction of the literacy practices of her home is reminiscent of Adrian Blackledge's (2001) findings about storytelling practices with Bangladeshi mothers. His research suggests that story-telling in the home language is both a gendered practice, as mothers take primary responsibility for telling their children stories, and gendering, in that one of its roles is the transmission of heritage customs governing 'culturally intelligible' (Butler, 1990) ways of doing gender. The mothers position themselves as bearers and nurturers of the heritage culture and, as Blackledge (2001) comments, believe that 'to learn to read and write Bengali was to be Bengali' (p. 66). It seems likely that the literacy practices in Aisha's home may have been similarly motivated and that Aisha responds positively to learning Urdu both as a way of maintaining the intimacy of her relationship with her mother and of adopting a 'dutiful daughter' positioning.

"Urdu is sweet; Punjabi seems like you're fighting" 
Interestingly, while Aisha displays strong identification with Urdu, she is hostile to Punjabi, her other heritage language. Despite her mother and other family members using Punjabi, Aisha does not identify with it as a language she can use to show belonging or develop intimacy:

A: $\quad$ My family background is Punjabi so mainly my parents actually speak Punjabi with each other. But with us it is in Urdu because I don't like Punjabi.

SP: $\quad$ You don't like it?

A: No ... I think it just seems like you're arguing when you're talking [Punjabi]. ... Urdu I think is really sweet ... when you talk it ... whereas when you speak Punjabi, it seems like you're fighting. It's not very formal ... it's like slang but I don't like it ... My parents [and] my family elders they all speak in Punjabi but with kids it is Urdu.

SP: So do you think that your parents are equally fluent in both?

A: $\quad$ Yes, definitely ...

SP: Have they always spoken to you in Urdu? Do you think they spoke to you in Punjabi at any time?

A: No, Urdu always. Because I have told them I don't like Punjabi, so don't talk to me in Punjabi.

SP: Where do you think that you formed that opinion that you didn't like Punjabi? Do you remember what started that off?

A: I think ... when I went to Pakistan (laughs) because all my family there speak Punjabi there ... but I didn't like it much ... I decided at a very early age that I liked Urdu more.

SP: $\quad$ You like the sound better?

A: $\quad$ Yeah, Urdu ... seems ... more polite whereas Punjabi it sounds as though you're just being rude.

SP: When you go to Pakistan and you're with your relatives ... are they speaking ... to you in Punjabi?

A: No, Urdu ... they speak both [but] with us they speak in Urdu ... But mostly all my cousins communicate in Urdu. It's just maybe once or twice that their parents say to speak Punjabi ... It's like ... maybe a generation gap, the older generation speak Punjabi and the younger generation speak Urdu (Interview 1).

Aisha dichotomises and genders her heritage languages, positioning Urdu as traditionally 'feminine', in her depiction of it as soft, 'really sweet' and 'polite', and Punjabi as stereotypically 'masculine', in associating it with aggression, 'fighting' and being 'rude'. As Aisha has been on regular visits to Pakistan since infancy, perhaps she associates Punjabi with life in the extended family in Pakistan and Urdu with an intimate motherdaughter relationship in London. She also links Urdu and Punjabi with life stage and age in the context of her extended family in Pakistan, in which she presents Urdu as the language of her contemporaries in opposition to Punjabi as the language of her elders. Her positioning of Punjabi speakers as using 'slang' in contrast to Urdu speakers, who 
she depicts as using more formal language, is suggestive of a Pakistani rural/ urban divide in which she associates Punjabi with a more traditional, older, less educated and village dwelling generation and Urdu with more youthful, educated and 'modern' city dwellers.

This association of Urdu with 'advancement' and Punjabi with 'backwardness' has echoes in the work of Maryon McDonald (1994) on Breton and French usage in Brittany. McDonald found that Breton mothers initiated language shift by using French with their children in preference to Breton. While they associated French, as the official language of the state, with urban life and upward mobility, they characterised Breton, as the local community language, as "(smelling) of cow-shit" (McDonald, 1994, p. 103). Perhaps, a similar reasoning informed Aisha's mother's choice of Urdu, rather than Punjabi, with her children and has come to shape Aisha's view of her home languages.

\section{Sita}

\section{"I learnt Tamil music with my mum"}

Born in 1981 in London, Sita is the oldest child of a Sri Lankan Tamil family and lives at home with her parents and her younger sister. While her parents were forced to flee Sri Lanka and seek asylum in Britain, Sita's knowledge of these events is constructed through her parental experience, the Tamil community and the media. Like Aisha, Sita presents herself as 'multilingual' and identifies Tamil as facilitating her relationship with her mother. In Sita's case, this intimacy has been created primarily through music, dance and films:

Tamil is our mother tongue language. When we watch films and listen to songs, and because I learnt [Tamil] music with my mum, I tend to use more Tamil ... When [my mum] describes things to me ... she tends to speak in Tamil and I have to reply in Tamil [because] there are things we can't talk [about] in English... Like dance ... when I have to express my feelings for a certain character, the teacher always explains it ... in Tamil rather than in English because it's more easier to follow (Interview 1).

Sita positions her heritage language as her 'mother tongue', learned mostly with her mother, who has also taught her to perform traditional Tamil music and songs. Sita has also been taking Tamil dance lessons since early childhood and now teaches it. Consequently, she appears well-versed in both the technical and aesthetic elements of traditional dance. Her portrayal of Tamil as embodied in movements and facial expressions suggests that she has come to associate particular movements and expressions, as well as language, with 'doing being' Tamil.

\section{"I'm more into my culture"}

Sita portrays her relationship with her sister as in English and uses it to contrast her own affiliation to Tamil with her sister's preference for English. Although she concedes that

s.preece@ioe.ac.uk - 11 - 
her sister shows some interest in Tamil traditions, this 'east/ west' opposition allows Sita to adopt a 'dutiful daughter' subject position and portray herself as complying with her parents' wishes:

We've been brought up the same way but because I'm more into my culture, more into dance I ... keep my flow of the language but for my sister she ... wouldn't utter [a word] in Tamil ... She does flow with the eastern culture but she talks more with western types and she ... loses contact [with her culture] (Interview 1).

Sita's affiliation to her heritage language and culture also appears highly influenced by the political situation in Sri Lanka, arising from two decades of civil war ${ }^{\mathrm{vi}}$ between the minority Tamils and majority Sinhala (Jeyaratnam Wilson, 1988), which has resulted in her family's asylum in Britain. In the interviews, Sita frequently positions herself a member of the Tamil diaspora, keen to convey the Tamil cause. She depicts her family as active members of the London Tamil community and the struggle for Eelam (expression for an independent Tamil homeland). She explains the critical role of the Tamil community Saturday school, which her parents helped establish, in maintaining and passing on Tamil cultural practices within the multicultural setting of London and preserving the Tamil diaspora as a distinct and separate ethnic group:

'We have so many different festivals [when] each comes ... you learn more things ... and you find out more stories ... why [these customs are] still going on ... it's something different and you ... keep it between yourselves, you ... keep your culture ... you're mixing with so many people, you're coming to university, you see Indians, Pakistanis, English, everything and I tend to talk with everyone the same way but I have to still keep my part of the world, keep my part of the language, my part of the culture. I can't actually lose that because if I don't learn, if I don't know my culture, eventually it's going to disappear ... so we have to carry it forward, keep it with us (Interview 1).

It seems highly likely that the Tamil school is an important 'community of practice' (Lave and Wenger, 1991) in Sita's life, facilitating her strong sense of Tamil identity. Talk about the school allows her to display strong affiliations with Sri Lanka as her 'imagined homeland' (Anderson, 1991) and of the Tamil language as an important marker of Tamil identity.

\section{"When I have children"}

Talk about her heritage language also enables Sita to imply that the Tamil-Sinhala civil war has resulted in her separation from indigenous Tamils and the loss of her birthright, through dislocating her from her 'homeland' and also 'mother tongue'. However, this talk also functions as a vehicle for the negotiation of 'culturally intelligible' (Butler, 1990) femininity within the Tamil community, in which Sita enacts a traditional subject position, imagining herself as a mother, who, like the mothers in Blackledge's (2001) study, will have responsibility for transmitting heritage language and customs with her children: 
'At the moment there's a war going on in Sri Lanka ... if the war wasn't going on, people wouldn't be coming ... to this country and I may have been born in Sri Lanka. All our people live there ... but we've moved to ... a first world country [where] people tend to mix ... westerners [and people from] different ... parts of the world. Eventually when I have children ... if I don't learn my own language, how [are] my children going to carry [the language] forward? ... If I don't learn my own language or my culture, you can't live together later on ... we need to carry on ... we need to carry this language (i.e. Tamil) through our life ... if we don't, we can't identify ourselves can we?' (Interview 1).

Sita seems to adopt this position partly as a political stance, as a method of fulfilling her duty to maintain the Tamil community given their struggle for Eelam, and partly as a way of enacting gender. As much literature comments (e.g. Phoenix, Woollett and Lloyd, 1991, Sunderland, 2004), motherhood is still presented as the norm for adult women and the most effective way for women to gain personal fulfilment. In families with strong affiliations to 'imagined homelands' (Anderson, 1991) and/ or separation from the mainstream host community, it seems likely that female family members will be positioned as "guardians of the home language" (Pavlenko and Piller, 2001, p. 27) with, as Aneta Pavlenko and Ingrid Piller (2001) comment, primary responsibility for maintaining the integrity of the community through transmitting heritage practices.

It is unlikely, however, that Sita will be able to fulfil this role fully as her affiliation to Tamil as a 'mother tongue' is not matched by her expertise. For Sita, therefore, this positioning seems both politically charged and a way of performing femininity. It facilitates her allegiance to the struggle for Eelam, in which Tamil, as her 'mother tongue', appears to be the 'embodiment of (Tamil) culture, ethnicity (and/ or) sense of nationality' (Mills, 2004, p. 166). Additionally, it enables her to perform "acceptable" femininity (Coates, 1996) within her community. For by imagining herself as a mother, responsible for maintaining Tamil language and customs with her children, she styles herself as heterosexual and abiding by the dominant discourse of heteronormativity.

\section{Discussion}

For the young women in this paper, talk on heritage languages is often bound up with negotiating a 'culturally intelligible' (Butler, 1990) gendered identity in relation to their peers, their families and me. In the peer group, British-born females often downplay either their expertise or their affiliation to their heritage languages. In some cases, this is done through talk in which the speakers 'mirror' each other's disclosures of difficulties and embarrassment in relation to their heritage languages. The activity of mirroring selfdisclosure is defined in Coates' (1996) work on conversation among female friends as "exchanged vulnerable talking", in which the speaker expects whatever she discloses to "(come) back" (pp. 88-9). Coates argues that this is a common feature of developing female friendships that both builds emotional ties and functions to establish boundaries of 'normal' and 'abnormal' femininity with peers (p. 89). As there are many examples of "exchanged vulnerable talking" in the all-female group data, a feature which is absent in 
the all-male talk, this practice may be both a strategy for establishing and maintaining friendships as 'newcomers' (Lave and Wenger, 1991) in higher education and a way of working to resolve conflicting subject positions. For in their talk, the British-born female participants frequently co-construct a floor in which it is normal for parents to expect their children to learn their heritage language and usual for children not to live up to these expectations. Underlying the 'embarrassment' that they associate with this situation is a heteronormative discourse in which they are positioned as future wives and mothers with responsibility for transmitting heritage practices to their children. While there is some resistance to this positioning, it is often difficult to sustain, suggesting that some of the participants are uncomfortable with subverting doing being a "dutiful daughter" (Coates, 1996). In this context, the adoption of 'girl power' discursive subject positions may be a way of resisting family relations and/ or exploring a more youthful, sassy and powerful persona. While the use of 'girl' for young women is frequently seen as patronising and diminishing in status, some of these young women embrace this positioning, perhaps because, as Whelehan (2000) comments, one positive connotation of 'girl' is the evoking of 'memories of choice and relative freedom before the travails of womanhood set in' ( $\mathrm{p}$. 39).

The interview setting appeared to give more opportunities for elaboration on heritage languages for both Aisha and Sita. While Saba and Davinder acted to curtail Aisha and Zarina's discussion of heritage languages, in the interview setting I encouraged Aisha to talk about these, which she seemed to welcome. For much of the time, she positions herself as a 'balanced bilingual' (Macnamara, 1967, 1969) and a 'balanced transnational' (Block, 2006, p. 209), through depicting herself as maintaining connections and identifications with her Pakistani heritage. Her discussion of her heritage languages as gendered allowed her to show a strong affiliation to Urdu as a 'feminine' language, through which she constructs an intimate mother-daughter relationship and portrays Pakistanis as educated, modern and progressive. Given that the first interview took place in the months following September $11^{\text {th }}$, it seems likely that her responses were shaped by these events as she presented herself and her community to me, a white British lecturer/researcher. Additionally, given our asymmetrical relationship, it seems likely that Aisha would be concerned with seeming cooperative and serious in the interviews, particularly given some of the frivolity of her peer group in the classroom.

Unlike the other female participants discussed here, Sita was in a mixed-sex peer group in the classroom dominated by Kavi, a male participant. Like her, Kavi was Tamil but he had been born in Sri Lanka and had experienced fleeing to Britain with his family. Perhaps as a consequence, he consistently adopted the position of expert speaker on Tamil, framing the talk around his experiences and interests and silencing Sita by consistently ignoring her contributions. In the interview setting, my questions appeared to allow Sita to counter this relatively powerless position. Through presenting Tamil as her 'mother tongue', she was able to occupy the floor as an expert speaker on the political situation in her 'imagined homeland' (Anderson, 1991) and the struggle for Eelam. This diaspora positioning also enabled her to subvert the asymmetrical lecturer/ student relationship as she took on the role of educating me about the political situation in Sri Lanka. Underpinning this positioning, however, were more culturally conservative 
discourses on gender relations, in which Sita identified with marriage and motherhood and responsibility for transmitting heritage language and culture.

\section{Conclusion}

In this article, I have discussed ways in which a group of primarily young female university students, mainly from British Asian families, performed femininities in talk about heritage languages. The data suggest that for these young women heritage languages are frequently bound up with gender and what it means for them to 'do being' a young woman. Much of their talk is underpinned by heteronormative discourses constituting femininity in terms of marriage, motherhood and maintenance of heritage language and customs. Interspersed with this, are conflicting subject positions offered by 'girl power' discourses constituting femininity in terms of youth, sassiness and individualism.

The talk of these young women also shows us something of the dynamic and ongoing development of London as a 'multicultural' and 'global' city (Block, 2006) and of what it means for young British Asian women to 'do being' a Londoner. As David Block (2006) points out, British Asians are firmly established as part of the ongoing discussions and developments related to multicultural London. For most of the young British Asian women here, London is their birthplace and likely to be their physical 'home' for the foreseeable future. Despite evidence for the adoption of 'transnational' and diaspora subject positions, London is also likely to be their primary emotional 'home', as they set about the process of establishing and maintaining adult relationships, which for most seem likely to include marriage and children. Additionally, all position themselves and are positioned as having connections with an established ethnolinguistic community in London: Urdu/ Punjabi-speaking Pakistanis, in the case of Aisha, Zarina, Saba and Davinder, Gujarati-speaking Indians, in the case of Leela, Maya and Seema, and Tamils, in the case of Sita. Sometimes they are ambivalent about these connections; sometimes they show much greater identification. This ambivalence and identification is not static; it shifts as they attempt to 'balance the self' (Eckert and McConnell-Ginet, 2003), by giving coherent accounts of self, across the salient communities of practice in their lives.

While I sometimes felt like a stranger in their worlds, there were moments when I experienced a greater sense of connection, particularly in matters of gender. There were many resonances from the "exchanged vulnerable talking" with women friends, the complexities of the 'dutiful daughter' positioning, the intimacy of mother-daughter relations to the desire to let off steam with the "girls"! For those of us teaching these young women, we will not only have enriching experiences, but also the challenge of making spaces within mass HE for them to explore imagining the self and of finding methods to encourage and support their adoption of 'subject/speaker' positions (Baxter, 2003) within academic discourses.

\section{Transcription conventions}


1. [Square brackets on top of each other indicates point where [speakers overlap

2. Words or syllables in CAPITALS indicates emphasis or volume

3. Full stop inside brackets (.) indicates pauses of less than one second

4. Numbers in brackets (3) indicate length of pauses to nearest second

5. Equals sign at the end of one utterance $=$ and start of the next utterance shows no audible gap between speakers

6. Question marks ? indicates question intonation

7. \%Phrases \% enclosed by percentage symbols are spoken very quietly

8. Double brackets around X's ((xxx)) shows that the speaker's utterance can't be discerned

9. Words with colons : show elongated vowel sounds

10. <Phrases in angled brackets> are comments by me as the transcriber

Many thanks to David Block, Vaidehi Ramanathan and Celia Roberts for comments on earlier versions of this paper.

\section{Bibliography}


i Names of participants and University are pseudonyms.

ii British government initiative to increase number of graduates in 18-30 year-old population to $50 \%$. Aimed at families with no history of higher education and/or people living in areas of the country with low proportion of graduates.

iii See Preece and Godfrey (2004) for discussion of student profile on programme.

iv See Preece (2006a) for fuller discussion of Aisha.

${ }^{v}$ See Preece (2004) for discussion. Note different pseudonyms for Awino, Biba and Leela.

vi The BBC (2005) report that the civil war has caused an estimated 64,000 deaths and around one million displaced people since 1983. 